Int. J. Electrochem. Sci., 15 (2020) 8479 - 8497

International Journal of

ELECTROCHEMICAL

SCIENCE

$\underline{\text { WWW.electrochemsci.org }}$

\title{
Study on Growth of Corrosion Scale on Various Iron Based Materials (Grey cast iron/Carbon steel/Ductile Iron) in Water Distribution Systems
}

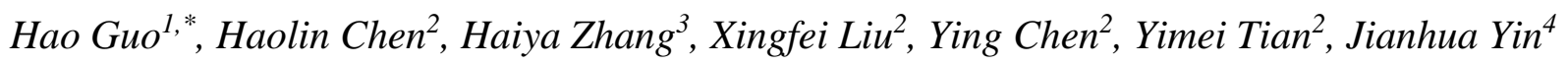 \\ ${ }^{1}$ The Institute of Seawater Desalination and Multipurpose Utilization, MNR(Tianjin), Tianjin 300192, \\ China \\ ${ }^{2}$ School of Environmental Science and Engineering, Tianjin University, Tianjin 300350, China \\ ${ }^{3}$ School of Environment, Tsinghua University, Beijing, 100084, China \\ ${ }^{4}$ Tianjin Zhonghai Water Treatment Technology Co., Ltd., Tianjin 300192, China \\ *E-mail: tjuguohao@163.com
}

doi: $10.20964 / 2020.09 .80$

Received: 3 May 2020 / Accepted: 13 July 2020 / Published: 10 August 2020

\begin{abstract}
A six-month corrosion experiment was conducted to examine the corrosion behaviour and scale growth of common iron materials (grey cast iron, carbon steel and ductile iron) in a simulated flow corrosion system. Coupon tests, electrochemical measurements and microanalysis were integrated to reveal the intrinsic connection between corrosion rate variation and physicochemical characteristics of corrosion scales, i.e., the corrosion control mechanism of the scales. The coupon tests showed ductile iron has the lowest corrosion rate and most stable corrosion scales. The EIS analysis confirmed that the corrosion scales have an effective control function for the electrochemical corrosion process. The outer scale layer of grey cast iron and carbon steel was more protective than the inner layer. However, for ductile iron, both the outer and inner layers of the scales were sufficiently dense to inhibit the corrosion process. The scale physicochemical analysis demonstrated the diversity of corrosion product composition and further confirmed the protect mechanism of the pipe scales: an effective corrosioncontrol scale layer is formed with a high content of stable $\alpha-\mathrm{FeOOH}$ and $\mathrm{CaCO}_{3}$ deposition, which limits the mass diffusion of the electrochemical corrosion process.
\end{abstract}

Keywords: Corrosion scales; Coupon test; EIS; Iron pipe; Water distribution system

\section{FULL TEXT}

(C) 2020 The Authors. Published by ESG (www.electrochemsci.org). This article is an open access article distributed under the terms and conditions of the Creative Commons Attribution license (http://creativecommons.org/licenses/by/4.0/). 